\title{
Cost to Save a Life in Heart Failure: Health Disparity Costs Lives
}

Philip Houck $^{1,2}$, Hari Dandapantula ${ }^{1,2}$, Donna Wilkinson ${ }^{3}$

1. Medicine/Cardiology, Texas A\&M Health Sciences Center, Temple, USA 2. Medicine/Cardiology, Baylor Scott \& White Health, Temple, USA 3. Cardiology/Nursing, Baylor Scott \& White Health, Temple, USA

Corresponding author: Philip Houck, phouck@sw.org

\section{Abstract \\ Objective}

The purpose of this paper is to assign a dollar value to life-saving medication, surgical procedures, and medical devices. The knowledge of the wide variation in the cost of drugs, surgery, and devices allows providers and patients to choose higher-valued therapies. Cost is a significant barrier to health. The current reimbursement system is complicated, representing a significant barrier to saving lives by promoting health disparity.

\section{Background}

The cost analysis of heart failure therapies is an important tool in the education of physicians, patients, and vendors of the intervention. The analysis demonstrates disparities between heart failure therapies. The cost to save a single life is calculated from annualized absolute mortality risk reduction, trial length, and estimated 10-year costs. The method allows comparisons of drugs, devices, and surgery.

\section{Methods}

The 10-year cost of drugs is 120 months times the cost of a drug/month as listed by the website GoodRX.com. The 10-year cost of surgery or device therapy was determined from a cost analysis found by a Google search of the literature. When wide ranges were reported, the mean value was selected.

1/absolute mortality risk reduction X 100 is the number needed to treat to save a life annualized for the mean length of the study. The cost to save a life can then be computed by the following formula:

Cost/life saved $=(10$-year cost/annualized absolute mortality risk reduction) $\mathrm{X}(100)$

\section{Results}

Beta-blockers and spironolactone had the lowest cost per life saved at $\$ 13,333$ and $\$ 21,818$, respectively. Defibrillators are the most expensive at $\$ 6,417,856$. Valsartan/sacubitril has a cost of $\$ 1,127,733$.

Received 07/16/2020 Review began 07/26/2020 Review ended 08/14/2020 Published 08/27/2020

() Copyright 2020

Houck et al. This is an open access article distributed under the terms of the Creative Commons Attribution License CC-BY 4.0., which permits unrestricted use, distribution, and reproduction in any medium, provided the original author and source are credited.

Dapagliflozin, the newest class of heart failure drug, costs $\$ 4,853,200$.

\section{Conclusions}

Calculating the cost to save a life gives insight into the value of therapies and demonstrates disparities. It is a means of comparing drugs and devices. New drug therapies are costly, not affordable, and serve as a barrier to the successful treatment of heart failure.

Categories: Cardiac/Thoracic/Vascular Surgery, Cardiology, Quality Improvement

Keywords: cost, absolute mortality, drugs, devices, surgery, payment maze

\section{Introduction}

Ordering life-saving medications and interventions in heart failure seems to be a simple task determined by the guidelines. The accomplishment of this goal is more difficult and requires the knowledge to order the intervention for the correct diagnosis; patient education, agreement to be treated, and compliance with the advice; and payment of the intervention by the patient, payer, or society. The goal of this paper is to assign a cost to lifesaving therapies. This analysis will help guide physicians who order interventions. The results will educate patients on the value of their therapies, which should improve compliance. Disparities in the costs of treatments may motivate vendors to reconsider their pricing analysis. The method of this analysis estimates the cost to save a life using a 10 -year cost of the intervention, the number of patients needed to treat to save one life, and the mean length of the study demonstrating an absolute mortality benefit.

\section{Background}


An economic analysis of medical treatment is a complicated calculation as outlined by Mark and Hlatky in their two-part article on medical economics [1]. The article provides a glossary of terms that are used in making an analysis to justify payments. A simpler approach is necessary to compare therapies for physicians, patients, vendors, and legislators. This simple approach has many caveats, including absolute mortality, benefits/harm, and coexisting comorbidities. The mortality benefits/harm are estimated from the literature. The cost of a drug is estimated from the website Good Rx and the costs of devices and interventions are obtained from the literature. The costs of surgical procedures and devices vary widely. The selection of 10-year costs of medications is seemingly arbitrary. Ten years is chosen since surgery and devices have a limited warranty, and 10 years seems a reasonable warranty.

\section{Materials And Methods \\ Mortality of therapies and comorbidity}

Tables 1-2 list cardiac central and peripheral performance parameters, therapies, and estimated annualized absolute mortality benefit/harm based on the current literature and the mean length of the trial. Table 3 lists common comorbidities associated with heart failure exacerbation, the estimated absolute mortality conferred by the presence of the comorbid condition, and the estimated mortality benefit of the intervention. The comorbidities are renal insufficiency, arrhythmia and conduction deficits, pulmonary hypertension, anemia, obstructive sleep apnea, infection, inflammation, lymphatic dysfunction, edema, ischemic heart disease, and ischemic mitral regurgitation. Tables 3 quantifies the net effect of comorbid conditions on heart failure mortality as well as the net benefit of treatment of these comorbid conditions. It emphasizes that comorbid conditions interfere with compensatory mechanisms and contribute to mortality. Multiple comorbid conditions within a single individual is not considered. Treating comorbidity can be costsaving. 


\section{Cureus}

\begin{tabular}{|c|c|c|c|}
\hline Cardiac Performance Parameter & Therapeutic Options to Improve Heart Failure & $\begin{array}{l}\text { Absolute Mortality Benefit (-) } \\
\text { Harm }\end{array}$ & Reference \\
\hline \multirow{6}{*}{ Preload } & Diuretics & $-8 \%$ & [2] \\
\hline & Nitrates & unknown & \\
\hline & Ultra-filtration & $-8 \%$ & [3-4] \\
\hline & CPAP & $-3.3 \%$ & [5-7] \\
\hline & Tolvaptan & $0 \%$ & [8] \\
\hline & Nesiritide & $0 \%$ & [9] \\
\hline \multirow{5}{*}{ Afterload } & Hydralazine/Nitrate & $4.2 \%$ & {$[10-11]$} \\
\hline & ACEI/ARB & $1.3 \%$ & [12-13] \\
\hline & Nesiritide & $0 \%$ & [9] \\
\hline & Valsartan/Sacubitril & $3.2 \%$ over $A, B, S$ & [14] \\
\hline & CPAP & $-3.3 \%$ & [5-7] \\
\hline \multirow{4}{*}{ Compliance } & Nesiritide & $0 \%$ & [9] \\
\hline & Valsartan/Sacubitril & $3.2 \%$ over $A, B, S$ & [14] \\
\hline & Ranexa & unknown & [15] \\
\hline & Spironolactone & $5.5 \%$ & {$[13,16]$} \\
\hline \multirow{3}{*}{ Contractility } & Digoxin & $0 \%$ & [17] \\
\hline & Sympathomimetics & $-1.5 \%$ & [18] \\
\hline & Phosphodiesterase Inhibitors & $-1.5 \%$ & [18] \\
\hline \multirow{4}{*}{ Geometry and Synchrony } & Diuretics & $-8 \%$ & [2] \\
\hline & Bi-V pacing & $4.1 \%$ & [19] \\
\hline & Surgery CABG & $1 \%$ & [20] \\
\hline & Surgery MVR & $2.1 \%$ & [21] \\
\hline
\end{tabular}

\section{TABLE 1: Cardiac performance parameters central acting}

Source [22]

A - ACEI/ARB, B - Beta-blockers, S - Spironolactone, CABG - Coronary bypass surgery, MVR - Mitral valve repair replacement, ( - ) denotes increases mortality, ACEI - Angiotensin-converting enzyme, ARB - Angiotensin II receptor blocker, SGLT2 - Sodium-glucose cotransporter 2 


\section{Cureus}

\begin{tabular}{|c|c|c|c|}
\hline Cardiac Performance Parameter & $\begin{array}{l}\text { Therapeutic Options to Improve Heart } \\
\text { Failure }\end{array}$ & $\begin{array}{l}\text { Absolute Mortality Benefit } \\
\text { Harm (-) }\end{array}$ & Reference \\
\hline \multirow{5}{*}{ Neuroendocrine } & ACEI/ARB & $1.3 \%$ & [12-13] \\
\hline & Spironolactone & $5.5 \%$ over $\mathrm{A}, \mathrm{B}$ & {$[13,16]$} \\
\hline & Beta-Blockers & $3.6 \%$ over $\mathrm{A}$ & [13] \\
\hline & Nesiritide & $0 \%$ short term & [9] \\
\hline & Valsartan/Sacubitril & $3.2 \%$ over $\mathrm{B}, \mathrm{S}$ & [14] \\
\hline \multirow{4}{*}{$\begin{array}{l}\text { Properties of Blood Vessel Agents that } \\
\text { reduce stiffness }\end{array}$} & Spironolactone & $5.5 \%$ over $A, B$ & {$[13,16]$} \\
\hline & Nesiritide & $0 \%$ short term & [9] \\
\hline & Valsartan/Sacubitril & $3.2 \%$ over $\mathrm{B}, \mathrm{S}$ & [14] \\
\hline & Calorie Restriction & Data limited & [23] \\
\hline \multirow{6}{*}{ Lymphatic function and Inflammation } & Sympathomimetics & $-1.5 \%$ & [18] \\
\hline & Phosphodiesterase I & $-1.5 \%$ & [18] \\
\hline & Digoxin & $0 \%$ & [17] \\
\hline & Nesiritide & $0 \%$ & [9] \\
\hline & Valsartan/Sacubitril & $3.2 \%$ over $\mathrm{B}, \mathrm{S}$ & [14] \\
\hline & Lymphedema Boots & Unknown & \\
\hline Kidney function SGLT2 inhibitor & Dapagliflozin & $1.2 \%$ & [24] \\
\hline
\end{tabular}

\section{TABLE 2: Peripheral acting performance parameters}

Source [22]

A - ACEI/ARB, B - Beta Blockers, S - Spironolactone, I - Inhibitors, ACEI - Angiotensin-converting enzyme, ARB - Angiotensin II receptor blocker, SGLT2 - Sodium-glucose cotransporter 2

\begin{tabular}{|c|c|c|c|c|}
\hline Comorbidity & $\begin{array}{l}\text { Absolute } \\
\text { Mortality (-) } \\
\text { Harm }\end{array}$ & Reference & Cause & Solution \\
\hline \multirow{8}{*}{$\begin{array}{l}\text { Renal insufficiency } \% \text { decrease per } \\
\mathrm{mL} / \mathrm{m} \text { of creatinine clearance }\end{array}$} & \multirow{8}{*}{$-1 \%$} & \multirow{8}{*}{ [25] } & Over diuresis & Stop diuresis \\
\hline & & & Bladder obstruction & $\begin{array}{l}\text { Bladder scan urology } \\
\text { consult }\end{array}$ \\
\hline & & & Neurogenic & $\begin{array}{l}\text { Straight } \\
\text { catheterization }\end{array}$ \\
\hline & & & Males - prostrate & Greenlight vaporization \\
\hline & & & Females - pelvic floor & $\begin{array}{l}\text { Straight } \\
\text { catheterization }\end{array}$ \\
\hline & & & Medications & Stop offending agent \\
\hline & & & Decreased cardiac output & $\begin{array}{l}\text { Increase cardiac } \\
\text { output }\end{array}$ \\
\hline & & & RV failure or restrictive LV & Increase heart rate \\
\hline & $-11 \%$ & [26] & Atrial fibrillation & Rate or rhythm control \\
\hline & $-19.4 \%$ & [27] & Ventricular tachycardia & $\begin{array}{l}\text { Treat CHF - anti- } \\
\text { arrhythmic }\end{array}$ \\
\hline
\end{tabular}




\section{Cureus}

\begin{tabular}{|c|c|c|c|c|}
\hline \multirow[t]{2}{*}{ Arrhythmia conduction } & & & Bradycardia - heart block & $\begin{array}{l}\text { Decrease blockers } \\
\text { pacemaker }\end{array}$ \\
\hline & $-3.1 \%$ & [28] & LBBB/IVCD & $\begin{array}{l}\mathrm{Bi}-\mathrm{V} \\
\text { pacemaker/defibrillator }\end{array}$ \\
\hline \multirow{5}{*}{ Pulmonary hypertension } & \multirow{5}{*}{$-25.6 \%$} & \multirow{5}{*}{ [5] } & Obstructive sleep apnea & CPAP \\
\hline & & & Lung disease & $\begin{array}{l}\text { Optimize medications - } \\
\mathrm{O} 2\end{array}$ \\
\hline & & & Diastolic dysfunction & $\begin{array}{l}\text { Medications - increase } \\
\text { HR }\end{array}$ \\
\hline & & & Valvular dysfunction & Valvular intervention \\
\hline & & & Pericardial disease & $\begin{array}{l}\text { Medications or } \\
\text { intervention }\end{array}$ \\
\hline \multirow{6}{*}{ Anemia } & \multirow{6}{*}{$-17.3 \%$} & \multirow{6}{*}{ [29] } & Iron deficiency & IV iron therapy \\
\hline & & & Inflammation & Colchicine \\
\hline & & & Renal insufficiency & Erythropoietin therapy \\
\hline & & & Myelodysplasia & Erythropoietin therapy \\
\hline & & & Testosterone deficiency & $\begin{array}{l}\text { Testosterone } \\
\text { replacement }\end{array}$ \\
\hline & & & Vitamin deficiencies & Vitamin supplement \\
\hline \multirow{3}{*}{ Infection } & \multirow{3}{*}{$-.8 \%$} & \multirow{3}{*}{ [30] } & Flu - viral illness & Immunizations \\
\hline & & & Bacterial Illness & Immunizations \\
\hline & & & Myocarditis endocarditis & IVIG \\
\hline Inflammation Hs-CRP & $-32 \%$ & & Abnormal immune response & Colchicine \\
\hline \multirow{3}{*}{ Lymphatic dysfunction } & \multirow{3}{*}{ Unknown } & & Thoracic duct injury & Lymphedema boots \\
\hline & & & Inhibiting medications & $\begin{array}{l}\text { Discontinue offending } \\
\text { agent }\end{array}$ \\
\hline & & & Infection tissue injury & Treat and support \\
\hline \multirow{4}{*}{ Edema } & \multirow{4}{*}{$-6 \%$} & & Dietary salt intake & Dietary management \\
\hline & & & Inflammation & Unknown \\
\hline & & & latrogenic medications & Remove agents \\
\hline & & & Lymphatic dysfunction & Lymphedema boots \\
\hline Coronary disease & $-28 \%$ & & $\begin{array}{l}\text { Recurrent myocardial } \\
\text { Infarction }\end{array}$ & Surgery, colchicine \\
\hline Ischemic mitral regurgitation & $-20 \%$ & & Annular dilation, LV geometry & Surgery \\
\hline Diabetes II & $-10.2 \%$ & & $\begin{array}{l}\text { Insulin excess, lack of } \\
\text { exercise, excessive calories }\end{array}$ & $\begin{array}{l}\text { Emplaglitizone, } \\
\text { exercise, good nutrition }\end{array}$ \\
\hline
\end{tabular}

\section{TABLE 3: Comorbidity/mortality - the heart failure cause/solution}

Source [22]

RV - Right ventricle; LV - Left ventricle, LBBB - Left bundle branch block, IVCD - Intraventricular conduction delay, CHF - Congestive heart failure, Bi-V - Biventricular, CPAP - Continuous positive airway pressure, IV - Intravenous, HR - Heart rate

The cost to save a life is estimated by the following formula using 10 -year cost, the mean length of the study to achieve the mortality reduction, and the absolute mortality risk reduction. The cost of drug therapy is 


\section{Cureus}

obtained from the website GoodRX.com. The 10-year cost is 120 months of the price of the drug for one month. The cost of surgery and device therapy was obtained by a Google Scholar search for cost analysis. When a spread of cost was listed the mean value was calculated.

Cost $/$ life saved $=(10$-year cost/annualized absolute mortality risk reduction $) X(100)$

Surveillance laboratory costs for drugs are not included since these costs are routine to general health evaluations. For devices, the follow-up expenses are also included since they are not trivial. Surgical therapies may also have follow-up costs, but they are not included.

\section{Results}

The authors' estimates (based upon currently available data), summarized from Tables 1-3 of perceived benefit/harm of therapies and co-morbidities, are listed. Using annualized absolute mortality risk reduction, the number of therapies needed to treat and save a life is computed. Table 4 is useful for comparing a therapy's mortality benefits and costs. Aldosterone inhibition appears to be a very successful strategy with a $5.5 \%$ reduction in mortality. This may be an overstatement. The cost to save a life is $\$ 21,818$. A newer heart failure medication is valsartan/sacubitril with 3.2\% mortality over ACEI. For fairness, the cost calculation used $4.5 \%$ absolute mortality by including the mortality benefit of ACEI at $1.3 \%$. This is appropriate since this trial compared valsartan/sacubitril to ACEI. Even with this additional mortality benefit

valsartan/sacubitril cost $\$ 1,127,733$, which is nearly 50 times the cost of spironolactone and is not quite as effective. The cost of valsartan/sacubitril is comparable to mitral valve repair with coronary bypass grafting. Biventricular pacing is favored over defibrillators since it offers a better mortality benefit of $4.1 \%$ versus $1.4 \%$. It may be better since this therapy positively remodels the heart. These devices are expensive, with defibrillators costing $\$ 6,417,856$ to save a life. The newest class of drugs demonstrating a heart failure mortality benefit are the sodium-glucose cotransporter 2 (SGLT2) agents of which dapagliflozin is an example. This agent costs $\$ 4,853,200$ to save a life. The 10 -year cost is nearly quadruple the cost of valsartan/sacubitril. Figure 1 is a graphical summary of the results.

\begin{tabular}{|c|c|c|c|c|}
\hline Medications/Interventions & $\begin{array}{l}\text { Absolute Mortality } \\
\text { Reduction \% }\end{array}$ & $\begin{array}{l}\text { Mean Study Follow- } \\
\text { Up Years }\end{array}$ & 10-Year Cost \$ & $\begin{array}{l}\text { Cost/Life Saved } \\
\$ / \text { Life }\end{array}$ \\
\hline Spironolactone & $5.5 \%$ & 2 & \$1199.99 & $\$ 21,818$ \\
\hline Hydralazine/nitrate & $4.2 \%$ & 1.5 & $\$ 3217.05$ & $\$ 71,428$ \\
\hline Beta-blockers & $3.6 \%$ & .81 & $\$ 4 / 9.99$ & $\$ 13,333$ \\
\hline Valsartan/sacubitril & $3.2 \%$ over ACEl & 2.1 & $\begin{array}{l}\$ 50748.00 \text {; includes benefit over } \\
\text { ACEI }(4.5 \%)\end{array}$ & $\$ 1,121,133$ \\
\hline ACEI/ARB & $1.3 \%$ & 3.45 & $\$ 202.80$ & $\$ 15,601$ \\
\hline Mitral valve repair & $2.1 \%$ & 4.6 & $\$ 60,000$ & $\$ 2,857,142$ \\
\hline CABG & $1 \%$ & 4.6 & $\$ 40,000$ & $\$ 4,000,000$ \\
\hline Biventricular pacing & $4.1 \%$ & 2.5 & $\$ 33500+48000$ & $\$ 993,902$ \\
\hline ICD & $1.4 \%$ & 1.7 & $41850+48000$ & $\$ 6,417,856$ \\
\hline Dapagliflozin [24] & $1.2 \%$ & 1.5 & $\$ 58238.40$ & $\$ 4,853,200$ \\
\hline
\end{tabular}

\section{TABLE 4: Absolute mortality benefit and cost of life saved}

ACEI - Angiotensin-converting enzyme, ARB - Angiotensin II receptor blocker, CABG - Coronary bypass surgery, ICD - Implantable cardioverterdefibrillator 


\section{Cureus}

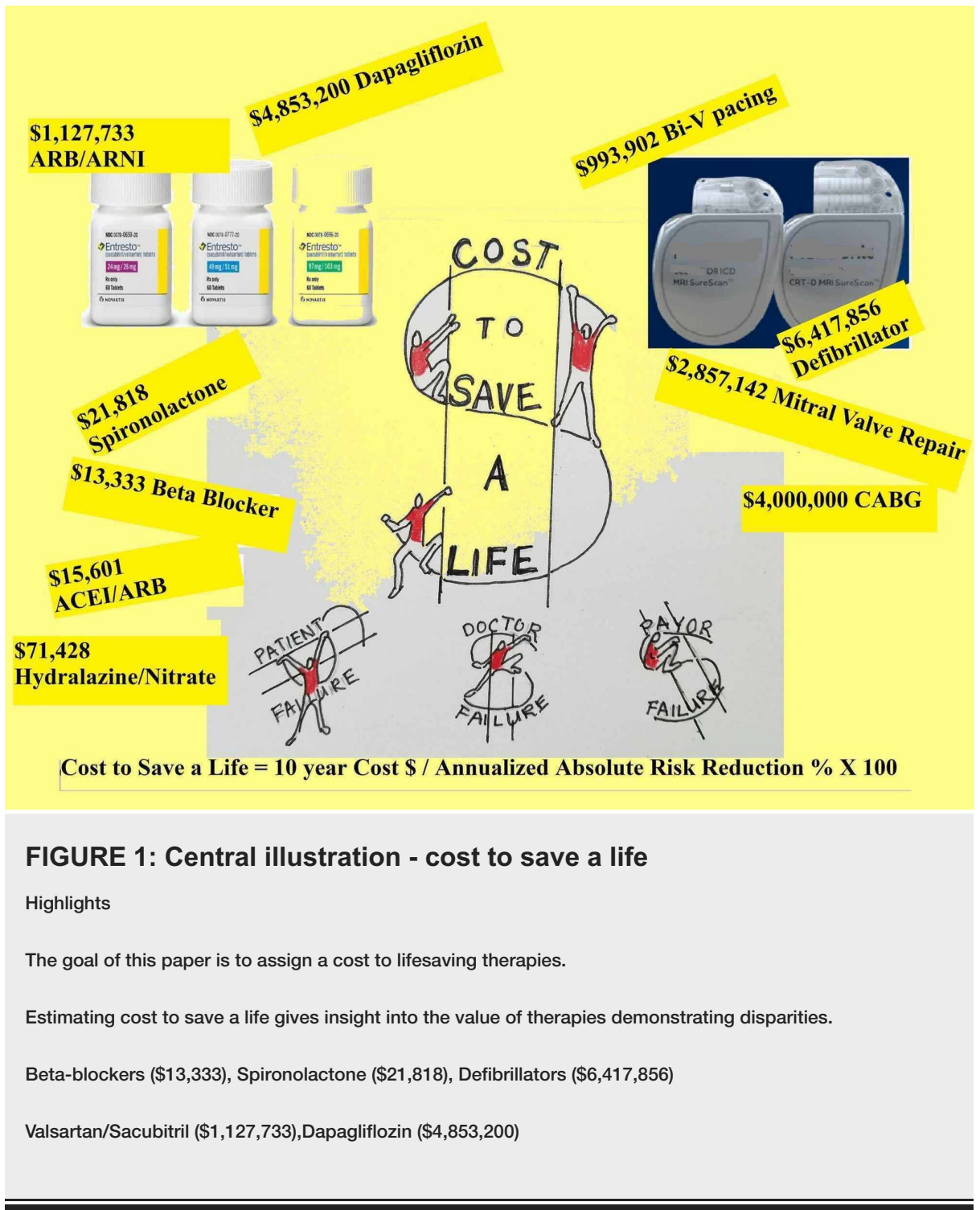

Discussion

\section{Mortality}

Mortality is an indisputable measure. This metric depends on the population studied, length of the study, underlying disease process, immediate cause of death, and other coinciding therapies. All metrics can affect indisputable mortality.

\section{Population studied}

Patients with the greatest mortality (New York Heart Association (NYHA) class 4, stage D) are often excluded from studies because they have high mortality. In this group, effective therapies show a significant mortality benefit as demonstrated in the spironolactone study noted below. Statisticians normalize population risk by relative mortality. The number needed to treat, however, is dependent on absolute mortality. The variability of population risk will bias the results. An example is the first vasodilator trial along with the subsequent Vasodilator-Heart Failure Trial (V-HEFT) I [23] and African-American Heart Failure Trial (A-HEFT) [10]. The population driving the success of hydralazine/nitrate therapy was a hypertensive African American population. The relative mortality benefit in the A-HEFT population was $44 \%$, with a $4.2 \%$ absolute mortality benefit. This therapy is considered a race-specific therapy since it was only studied in African Americans. However, it is a likely therapy for those depleted in nitric oxide or over producers of free radicals [11]. The mechanism is not entirely clear. Hypertensive Caucasians, Asians, and Hispanics can have the same hypertensive genes as African Americans and could also benefit from this therapy. The $4.2 \%$ absolute mortality benefit in the A-HEFT trial may not be generalizable in a broader heart failure population since the trial selected a race-specific hypertensive population. It is equally true that failure to use this medication in hypertensive non-African Americans may exclude patients who could benefit from this therapy. 
suggesting that aldosterone blockade is perhaps the most powerful heart failure strategy [16]. Aldosterone is a primitive hormonal regulator of cations and fibrosis; thus, blocking its action may be quite advantageous in preventing long-term fibrosis in a failing heart. However, spironolactone was studied in a high-risk population in the setting of co-treatment with beta-blockers and renin-angiotensin inhibitors. Thus, its benefit may be overestimated blunted by the advantage of co-therapies.

\section{Length of the study - long-term remodeling is not assessed}

Drugs used for acute exacerbations are not assessed for long-term benefits. An example is giving nesiritide only for acute exacerbation instead of continuous therapy. Continuous exposure to Brain Natriuretic Peptide (BNP) could signal repair mechanisms that positively remodel the heart over years of therapy. A mortality benefit may not be present for short duration therapy but could be significant over the long term with positive remodeling. A therapy that positively remodels the heart will have compounded benefit over a medication that simply halts decay. The first neprilysin inhibitor, valsartan/sacubitril, could have favorable structural remodeling of the heart through this action. It has not been studied in this context.

After crossing a threshold of benefit, trials are stopped. Therapies that rebuild an ailing heart may have an increasing mortality benefit over time. This benefit is not evident during the trial. Therapies that only have a short-term benefit with no positive change in the structure of the heart may appear favorable in shortduration trials but would not be expected to produce a long-term benefit. Examples are beta-blocker therapy, which induces favorable cardiac remodeling, versus left ventricular assist devices, which cause atrophy of myocardial tissue and degradation of the valves and endothelium.

\section{Underlying disease process}

Heart failure is a pleomorphic process consisting of preserved versus impaired systolic function, myofibril disease, structural heart disease, electrical system disease, inflammation, and tissue injury; thus, one size does not fit all. Cardiac abnormalities coexist with peripheral disease processes that interfere with compensatory mechanisms. The diversity of the study population can result in erroneous conclusions. Results from a highly selected population may not be successfully utilized in a general population, which may have a different disease process. An example of this concept is left bundle branch block and pacemakermediated cardiomyopathy that could potentially be treated with electrical therapy alone [19]. Another example is the treatment of central apnea as opposed to obstructive apnea. Central apnea is a compensatory mechanism in advanced heart failure, reducing diaphragmatic work. Treatment of this process leads to a worse outcome.

\section{Immediate cause of death}

Expert adjudication committees assign all-cause death and death due to heart failure. Death certificates are notoriously poor. A heart failure patient lacks reserve, and, in this respect, death can be attributed to heart failure. In most cases, there is an intervening condition that caused further decompensation without a substantial change in the structure of the failing heart. The specific cause of death interfered with peripheral compensatory mechanisms. Infections, anemia, falls, renal failure, obstructive uropathy, and arrhythmias are common causes of decompensation that result in a "heart failure death." These deaths are manifestations of peripheral failure rather than a functional change in the heart's central performance parameters.

\section{Co-existing therapies}

Different risk populations are treated with different baseline therapies. Ethics requires providing a previously determined successful therapy. As a result, new therapies are added to old therapies, and the new mortality benefit is a measure of an add-on therapy. The new therapy is dependent on the coinciding therapies. This rationale may be faulty since interactions between therapies could lead to adverse results such as an excessive blockade of the neuroendocrine system with hyperkalemia and excessive pre-load reduction with hypotension.

Medication errors increase when patients are hospitalized and when a greater number of medications are used. Examples include medications that interfere with creatinine clearance or interact with warfarin. More common therapies contributing to death include diuretics that appear to induce cardiorenal syndrome. Sympathomimetic/phosphodiesterase inhibitors that are used to treat cardiorenal syndrome induce arrhythmias and myocardial apoptosis. These medications are used to improve symptoms and help restore compensation at the expense of increased mortality.

The recommendations for beta-blockers, ACEI/ARB, valsartan-neprilysin inhibitors, spironolactone, defibrillators, and biventricular pacing are generally accepted. Tables 1-2 suggests that these therapies have modest improvements in survival. The greatest improvement is spironolactone, with hydralazine/nitrate in the second place (5.5\% and $4.2 \%$ reductions in absolute mortality, respectively). Despite the favorable profile of these agents, they are underutilized [13]. Also, despite the known increase in mortality of the preload reduction strategy, sympathomimetic agonists, and phosphodiesterase inhibitors, these agents are overutilized. The knowledge of mortality reduction should help Physicians improve the underutilization of 
spironolactone, hydralazine/nitrate. Patient education and compliance should be bolstered by hard absolute mortality numbers.

\section{The major barrier to therapies is cost}

The third requirement for the successful treatment of heart failure is the payment of the intervention by the patient, payer, or society. Figure 2 is an attempt to summarize the maze nurses navigate to obtain patient assistance. The figure demonstrates multiple failure points preventing a patient from receiving the drug from the pharmacy. These failures are a result of a patient's and health care provider's inability to understand the benefits, co-pays, gaps, donut holes, deductibles, and assistance that is available from drug companies. Financial forms, appeals, queries from insurance plans, tiers, tier exceptions, and, literally, multiple faxes, and peer reviews are all designed to be barriers that prevent lives from being saved.

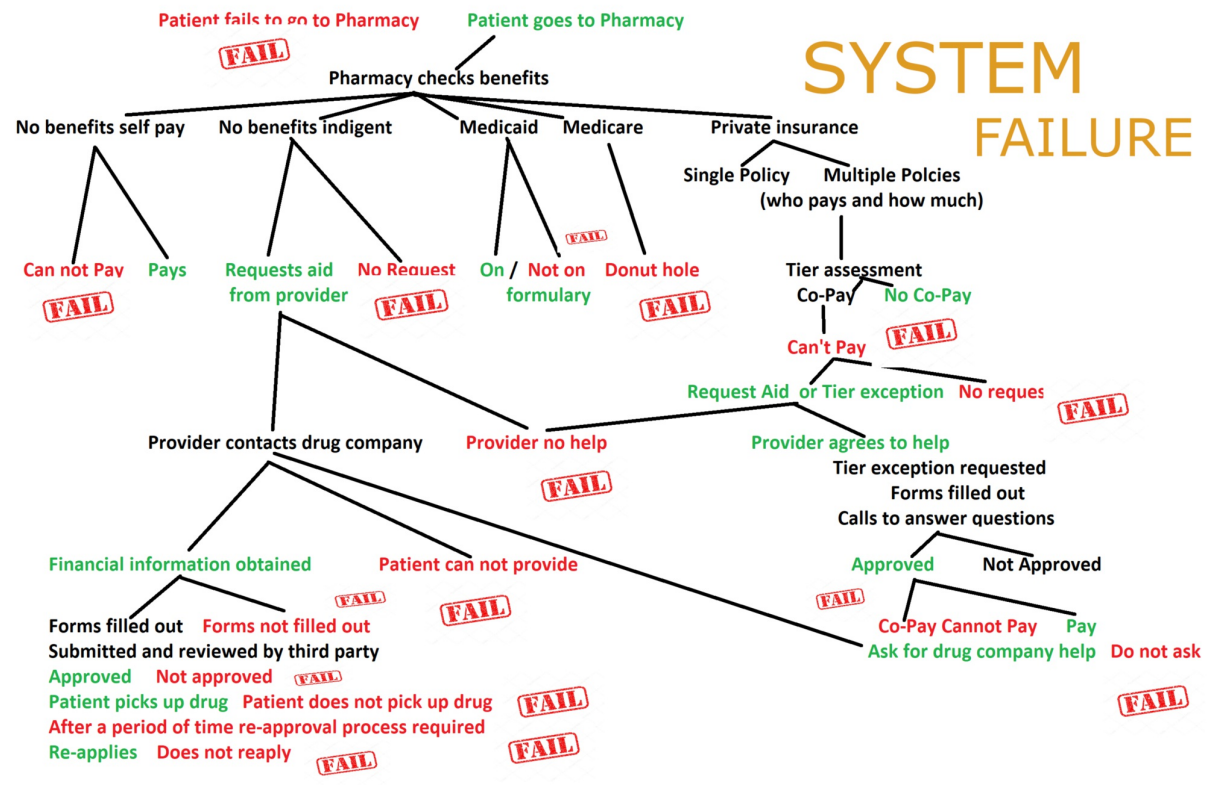

FIGURE 2: Incomplete payment maze

Doctors have licensed prescriptive authority but have been usurped by third-party agents. The following letter has been useful in reminding third-party agents of the physician's role, responsibility, and liability in caring for patients. The doctor's orders should be completed and not negotiated. The letter is my personal communication (Houck, Philip), which I asked our hospital lawyers to draft to combat payors form usurping my prescriptive authority.

"Your pre-authorization requirement for this medication is interfering with my prescriptive authority and my ability to properly treat this patient. Your policy makes it difficult or impossible to fully observe the standard of care for treating this patient's medical condition. When I give an order for a particular treatment, it is my intention that the order be carried out in a timely manner. Any delay in the implementation of the therapies prescribed by me could have disastrous effects on patient care. In the event that the delay created by your policy proximately causes any adverse consequences or harm to this patient, it will be my position that you should be held liable for whatever legal damages result. I urge you to withdraw your pre-authorization requirement for this medication."

\section{Implications of non-affordable medications and devices}

First, heart failure therapy is expensive. The above analysis is for single interventions. Most patients receive multiple interventions. It is not known if multiple interventions will have a greater absolute mortality benefit or just add to the cost.

Second, the cost of valsartan/sacubitril is 50 times more than that of other heart failure medications. The 10 -year cost of dapagliflozin is double the cost of valsartan/sacubitril, over 4-million dollars. These agents are overpriced needlessly and are a barrier to patient treatment. The cost of 10 years of dialysis should not be equivalent to the 10-year cost of a drug. The margin on these two drugs is incredibly high versus the overhead of dialysis. The pricing of new medications should be based on margin, utilization, and value. Device therapies need to be cheaper and more precisely applied to improve the number needed to treat, lowering the cost. 
Third, medical disparity, even with drug and device company financial assistance, results in failure to deliver life-saving therapies. Barriers to financial assistance need to be eliminated.

Physician leadership should take back the prescriptive authority from third-party payees. Physicians should demand a simpler method to obtain financial assistance for all patients.

\section{Conclusions}

The simple method to estimate the cost to save a life gives insight into the value of therapies and into disparities. It is a means of comparing drugs and devices. Competition of health dollars will demand justification of costs and greater precision in delivering therapies. Physician leadership is currently lacking, with third parties usurping physician authority.

\section{Additional Information \\ Disclosures}

Human subjects: Consent was obtained by all participants in this study. Baylor Scott \& White Health Temple IRB issued approval N/A. The paper is a search of the literature. Each paper cited had appropriate IRB and patient consent. My initial statement that the paper did not include human subjects implied no new subjects were enrolled in the trial and IRB was not required to perform this study of the literature. Animal subjects: All authors have confirmed that this study did not involve animal subjects or tissue. Conflicts of interest: In compliance with the ICMJE uniform disclosure form, all authors declare the following: Payment/services info: All authors have declared that no financial support was received from any organization for the submitted work. Financial relationships: All authors have declared that they have no financial relationships at present or within the previous three years with any organizations that might have an interest in the submitted work. Other relationships: All authors have declared that there are no other relationships or activities that could appear to have influenced the submitted work.

\section{Acknowledgements}

The authors would like to thank Hicks I II, Albert J M.D., Chukwu, Ebere O M.D., Nikolaidis, Lazaros A M.D.

\section{References}

1. Mark DB, Hlatky MA: Medical economics and the assessment of value in cardiovascular medicine: part I . Circulation. 2002, 106:516-520. 10.1161/01.cir.0000021407.93752.7b

2. Ahmed A, Husain A, Love TE, et al.: Heart failure, chronic diuretic use, and increase in mortality and hospitalization: an observational study using propensity score methods. Eur Heart J. 2006, 27:1431-1439. 10.1093/eurheartj/ehi890

3. Marenzi G, Muratori M, Cosentino ER, et al.: Continuous ultrafiltration for congestive heart failure: the CUORE trial. J Card Fail. 2014, 20:378. 10.1016/j.cardfail.2013.11.004

4. Costanzo MR, Guglin ME, Saltzberg MT, et al.: Ultrafiltration versus intravenous diuretics for patients hospitalized for acute decompensated heart failure. J Am Coll Cardiol. 2007, 49:675-683. 10.1016/j.jacc.2006.07.073

5. Cowie MR, Woehrle H, Wegscheider K, et al.: Adaptive servo-ventilation for central sleep apnea in systolic heart failure. N Engl J Med. 2015, 373:1095-1105. 10.1056/NEJMoa1506459

6. Marshall NS, Wong KKH, Liu PY, Cullen SRJ, Knuiman MW, Grunstein RR: Sleep apnea as an independent risk factor for all-cause mortality: the Busselton Health Study. Sleep. 2008, 31:1079-1085.

7. Arzt M, Woehrle H, Oldenburg O, et al.: Prevalence and predictors of sleep-disordered breathing in patients with stable chronic heart failure: the SchlaHF Registry. JACC Heart Fail. 2016, 4:116-125. 10.1016/j.jchf.2015.09.014

8. Konstam MA, Gheorghiade M, Burnett JC, et al.: Effects of oral tolvaptan in patients hospitalized for worsening heart failure. The EVEREST Outcome Trial. JAMA. 2007, 297:1319-1331. 10.1001/jama.297.12.1319

9. Abraham WT, Adams KF, Fonarow GC, et al.: In-hospital mortality in patients with acute decompensated heart failure requiring intravenous vasoactive medications: an analysis from the Acute Decompensated Heart Failure National Registry (ADHERE). J Am Coll Cardiol. 2005, 46:57-64. 10.1016/j.jacc.2005.03.051

10. Taylor AL, Ziesche S, Yancy C, et al.: Combination of isosorbide dinitrate and hydralazine in blacks with heart failure. N Engl J Med. 2004, 351:2049-2057. 10.1056/NEJMoa042934

11. Farag M, Mabote T, Shoaib A, Zhang J, Nabhan AF, Clark AL, Cleland JG: Hydralazine and nitrates alone or combined for the management of chronic heart failure: a systematic review. Int J Cardiol. 2015, 196:61-69. 10.1016/j.ijcard.2015.05.160

12. Flather MD, Yusuf S, Køber L, et al.: Long-term ACE-inhibitor therapy in patients with heart failure or leftventricular dysfunction: a systematic overview of data from individual patients. ACE-Inhibitor Myocardial Infarction Collaborative Group. Lancet. 2000, 355:1575-1581. 10.1016/s0140-6736(00)02212-1

13. Fonarow GC, Yancy CW, Hernandez AF, et al.: Potential impact of optimal implementation of evidencebased heart failure therapies on mortality. Am Heart J Volume. 2011, 161:1024-1030. 10.1016/j.ahj.2011.01.027

14. McMurray JJ, Packer M, Desai AS, et al.: Angiotensin-neprilysin inhibition versus enalapril in heart failure . N Engl J Med. 2014, 371:993-1004. 10.1056/NEJMoa1409077

15. Sossalla S, Wagner S, Rasenack EC, et al.: Ranolazine improves diastolic dysfunction in isolated myocardium 
from failing human hearts - role of late sodium current and intracellular ion accumulation. J Mol Cell Cardiol. 2008, 45:32-43. 10.1016/j.yjmcc.2008.03.006

16. Pitt B, Zannad F, Remme WJ, et al.: The effect of spironolactone on morbidity and mortality in patients with severe heart failure. Randomized Aldactone Evaluation Study Investigators. N Engl J Med. 1999, 341:709717. 10.1056/NEJM199909023411001

17. Digitalis Investigation Group: The effect of digoxin on mortality and morbidity in patients with heart failure. N Engl J Med. 1997, 336:525-553. 10.1056/NEJM199702203360801

18. Dec GW: Acute decompensated heart failure: the shrinking role of inotropic therapy . J Am Coll Cardiol. 2005, 46:65-67. 10.1016/j.jacc.2005.04.007

19. Cleland JG, Daubert JC, Erdmann E, Freemantle N, Gras D, Kappenberger L, Tavazz L: The effect of cardiac resynchronization on morbidity and mortality in heart failure. N Engl J Med. 2005, 352:1539-1549. 10.1056/NEJMoa050496

20. Carson P, Wertheimer J, Miller A, et al.: The STICH trial (surgical treatment for ischemic heart failure): mode-of-death results. JACC Heart Fail. 2013, 1:400-408. 10.1016/j.jchf.2013.04.012

21. Deja MA, Grayburn PA, Sun B, et al.: Influence of mitral regurgitation repair on survival in the surgical treatment for ischemic heart failure trial. Circulation. 2012, 125:2639-2648.

10.1161/CIRCULATIONAHA.111.072256

22. Houck P, Dandapantula H, Hardegree E, Massey J: Why we fail at heart failure: lymphatic insufficiency is disregarded. Cureus. 2020, 12:e8930. 10.7759/cureus.8930

23. Heilbronn LK, Ravussin E: Calorie restriction and aging: review of the literature and implications for studies in humans. Am J Clin Nutr. 2003, 78:361-369. 10.1093/ajcn/78.3.361

24. McMurray JJV, Solomon SD, Inzucchi SE, et al.: Dapagliflozin in patients with heart failure and reduced ejection fraction. N Engl J Med. 2019, 381:1995-2008. 10.1056/NEJMoa1911303

25. McAlister FA, Ezekowitz J, Tonelli M, Armstrong PW: Renal insufficiency and heart failure. Prognostic and therapeutic implications from a prospective cohort study. Circulation. 2004, 109:1004-1009. 10.1161/01.CIR.0000116764.53225.A9

26. Dries DL, Exner DV, Gersh BJ, Domanski MJ, Waclawiw MA, Stevenson LW: Atrial fibrillation is associated with an increased risk for mortality and heart failure progression in patients with asymptomatic and symptomatic left ventricular systolic dysfunction: a retrospective analysis of the SOLVD trials. J Am Coll Cardiol. 1998, 32:695-703. 10.1016/s0735-1097(98)00297-6

27. Doval HC, Nul DR, Grancelli HO, et al.: Nonsustained ventricular tachycardia in severe heart failure. Independent marker of increased mortality due to sudden death. Circulation. 1996, 94:3198-3203. 10.1161/01.cir.94.12.3198

28. Tabrizi F, Englund A, Rosenqvist R, Wallentin L, Stenestrand U: Influence of left bundle branch block on long-term mortality in a population with heart failure. Eur Heart J. 2007, 28:2449-2455. 10.1093/eurheartj/ehm262

29. Groenveld HF, Januzzi JL, Danman K, Wijngaarden J, Hillege HL, van Veldhuisen DJ, van der Meer P: Anemia and mortality in heart failure patients: a systematic review and meta-analysis. J Am Coll Cardiol. 2008, 52:818-827. 10.1016/j.jacc.2008.04.061

30. Panhwar MS, Kalra A, Gupta T, Kolte D, Khera S, Bhatt DL, Ginwalla M: Effect of influenza on outcomes in patients with heart failure. JACC Heart Fail. 2019, 7:112-117. 10.1016/j.jchf.2018.10.011 